\title{
Seleção precoce de espécies de Passiflora resistente a fusariose
}

\author{
Sandra da Costa Preisigke ${ }^{1}$, Lucas Pereira da Silva ${ }^{1}$, Milson Evaldo Serafim², Claudio Horst Bruckner ${ }^{3}$, Kelly Lana \\ Araújo $^{1}$, Leonarda Grillo Neves ${ }^{1}$
}

${ }^{1}$ Universidade do Estado de Mato Grosso, Departamento de Genética e Melhoramento de Plantas, Av. Tancredo Neves, 1095 - Cavalhada II, CEP 78200-000 - Cáceres - MT; ${ }^{2}$ Instituto Federal de Educação, Ciência e Tecnologia de Mato Grosso, Departamento de solos, Av. dos Ramires, s/n - CEP: 78200-000, Cáceres - MT; ${ }^{3}$ Universidade Federal de Viçosa, Programa de Pós-Graduação em Fitotecnia Campus Universitário, CEP: 36570 900, Viçosa - MG.

Autor para correspondência: Sandra da Costa Preisigk (sandrapreisigke@hotmail.com)

Data de chegada: 05/02/2017. Aceito para publicação em: 27/04/2017.

$10.1590 / 0100-5405 / 175390$

\section{RESUMO}

Preisigke, S.C.; Silva, L.P.; Serafim, M.E.; Bruckner, C.H.; Araújo, K.L.; Neves, L.G. Seleção precoce de espécies de Passiflora resistente a fusariose. Summa Phytopathologica, v.43, n.4, p.321-325, 2017.

O maracujazeiro azedo é uma importante fruteira amplamente produzida e consumida no Brasil. A produção e produtividade estão ameaçadas por vários problemas fitossanitários. Uns dos mais importantes é a fusariose, causada pelo fungo Fusarium oxysporum $f$. sp. passiflorae. Esta doença não tem controle eficiente. Neste sentido o objetivo deste trabalho foi avaliar a resposta de plantas, em estágio de muda, de 14 espécies de Passiflora mediante a inoculação de F. oxysporum f. sp. passiflorae cultivadas em solução nutritiva. As espécies utilizadas no Screening foram: P. quadrangularis, P. nitida, P. foetida, P. tenuifila, P. alata, P. setacea, P. cincinnata, P. mucronata, P. micropetala, P. suberosa, P. morifolia,
P. eichleriana $P$. edulis e $P$. coccinea. Quatro mudas de cada genótipo foram inoculadas por imersão das raízes numa suspensão de $1 \times 10^{6}$ esporos $\mathrm{mL}^{-1}$, durante 24 horas e, em seguida, transplantada para potes contendo solução nutritiva. As plantas foram avaliadas diariamente por 40 dias para a ocorrência de sintomas de murcha e morte. Foram obtidos o período de sobrevivência e a taxa de mortalidade. O método de imersão das raízes por 24 horas e a substituição de solo por solução nutritiva foi eficiente na distinção dos genótipos resistentes. Houve variabilidade intraespecíficas em relação a doença. As espécies mais resistentes foram P. foetida, P. mucronata, $P$. nitida e P. morifolia.

Palavras-chave: Maracujá azedo; Fusarium oxysporum f. sp. passiflorae; resistência genética.

\section{ABSTRACT}

Preisigke, S.C.; Silva, L.P.; Serafim, M.E.; Bruckner, C.H.; Araújo, K.L.; Neves, L.G. Early selection of Passiflora species resistant to fusariosis. Summa Phytopathologica, v.43, n.4, p.321-325, 2017.

Passion fruit is an important fruit vine widely produced and consumed in Brazil. Production and productivity have been threatened by several phytosanitary problems. One of the most important problems is fusariosis, caused by the fungus Fusarium oxysporum $f$. sp. passiflorae. This disease has no efficient control. Thus, the aim of this study was to evaluate the response of plants of 14 Passiflora species, in the stage of seedling, through inoculation of F. oxysporum $f$. sp. passiflorae grown in nutritive solution. The species used in the screening were P. quadrangularis, P. nitida, P. foetida, P. tenuifila, P. alata, P. setacea, P. cincinnata, P. mucronata, P. micropetala, P. suberosa, P. morifolia
P. eichleriana P. edulis and P. coccinea. Four seedlings of each genotype were inoculated by immersion of roots in a suspension of $1 \times 10^{6}$ spores $\mathrm{mL}^{-1}$ during 24 hours and then transplanted into pots containing nutritive solution. Plants were daily evaluated during 40 days for the occurrence of wilt symptoms and death. The survival period and the mortality rate were obtained. The method of root immersion for 24 hours and the replacement of soil by nutritive solution were efficient in distinguishing the resistant genotypes. There was intraspecific variability in relation to the disease. The most resistant species were $P$. foetida, P. mucronata, P. nitida and P. morifolia.

Keywords: Passion fruit, Fusarium oxysporum f. sp. Passiflorae, genetic resistance.

O maracujazeiro azedo (Passiflora edulis Sims) é a espécie mais conhecida e estudada dentro do gênero Passiflora. O Brasil, desde a década de 70, vem se destacando como maior consumidor e produtor mundial desta fruteira. Porém, problemas fitossanitários ameaçam o setor produtivo dessa cultura. As doenças causadas por patógenos de solo são as mais preocupantes pois não tem nenhuma forma de controle eficiente. Dentre essas doenças, destaca-se a fusariose ou murcha de Fusarium causada pelo fungo Fusarium oxysporum $f$. $s p$. passiflorae (15).

O fungo $F$. oxysporum f. sp. passiflorae coloniza os vasos das plantas através de pequenos ferimentos ou aberturas naturais nas raízes, obstruindo os vasos causando murcha e consequentemente a morte da planta. É uma doença que provoca grandes perdas na produção e produtividade, além de inviabilizar o cultivo em áreas afetadas durante anos $(1,25)$. Vários trabalho vem sendo desenvolvidos a fim de obter uma estratégia eficiente de controle dessa doença. Estudos como a utilização do resíduo orgânico (8), irradiação por raios gamas (9) e controle com Trichoderma (2).

O uso de cultivares resistentes é muito eficiente no controle da maioria das doenças causadas por patógenos de solo $(17,22)$. Porém, não existem registro de cultivares de maracujazeiro resistentes a fusariose. Para desenvolver cultivares melhoradas é necessário explorar a variabilidade genética entre as espécies de Passiflora que podem revelar fontes de resistência. Para isso, é necessário que os métodos de 
inoculação do patógeno e caracterização da resistência sejam eficazes. As formas utilizadas para avaliação da resistência genética a essa doença tem sido o plantio em áreas com histórico da doença $(5,13)$, emprego de métodos in vitro (10) e inoculação do patógeno (22).

Apesar dos estudos citados, não há uma elucidação de espécies resistentes e de metodologias para diagnóstico precoce e mais preciso de plantas resistentes. Sendo assim, este trabalho teve como objetivo avaliar a resposta de plantas de várias espécies de Passiflora ao fungo F. oxysporum f. sp. passiflorae cultivadas em solução nutritiva.

\section{MATERIAL E MÉTODOS}

O experimento foi realizado no laboratório de Melhoramento de Planta da Universidade do Estado de Mato Grosso (UNEMAT) situada no município de Cáceres, região sudoeste de Mato Grosso.

Quatorze espécies de Passiflora oriundas da coleção de trabalho da UNEMAT foram utilizada no Screening para resistência ao Fusarium oxysporum f. sp. Passiflorae, Avaliaram-se as espécies: $P$. quadrangularis, P. nitida, P. foetida, P. tenuifila, P. alata, P. setacea, P. cincinnata, P. mucronata, P. micropetala, P. suberosa, P. morifolia, $P$. eichleriana $P$. edulis e $P$. coccinea. Realizou-se a semeadura em bandejas de isopor de 128 células com substrato Plantmax ${ }^{\circledR}$. A inoculação foi realizada em plantas com 60 dias após a semeadura.

Foi utilizado o isolado FOP18 de F. oxysporum f. sp. passiflorae pertencente a Micoteca do laboratório de Melhoramento de Genético de Plantas da UNEMAT, Campus de Cáceres. Para evitar a interferência de variabilidade genética do fungo, utilizou-se na inoculação um isolado obtido de cultura monospórica. Na produção do inóculo, micélios do fungo preservado em segmentos de papel filtro foram repicados para placas de Petri contendo o meio de cultura BDA (batata-dextrose-ágar). Em seguida, as placas foram incubadas em câmara de crescimento (B.O.D.), com temperatura de $25^{\circ} \mathrm{C}$ com fotoperíodo de 12 horas, durante sete dias.

Após esse período, foram vertidos $10 \mathrm{~mL}$ de água destilada às placas de Petri contendo a colônia do fungo para a obtenção da suspensão de esporos. Esta foi preparada minutos antes da inoculação, sendo a concentração ajustada para $1 \times 10^{6}$ esporos $\mathrm{mL}^{-1}$, com auxílio de uma câmara de Neubauer.

O procedimento utilizado na inoculação foi o de raízes lavadas. As plantas foram retiradas das bandejas, o sistema radicular foi lavado em água destilada e partes das raízes foram cortadas com o auxílio de uma tesoura estéril, em seguida, as raízes foram imersas em 100 $\mathrm{mL}$ de suspensão de conídios em potes plásticos de $200 \mathrm{~mL}$, a raízes ficaram na suspensão durante 24 horas. Uma planta de cada espécie foi mantida como testemunha. Para as testemunhas de cada espécie, o procedimento foi o mesmo, diferiu somente que no lugar da suspensão contendo o patógeno foi colocada apenas água destilada. Após o período de 24 horas, a suspensão foi retirada e adicionada $100 \mathrm{~mL}$ de solução nutritiva proposta por Hoagland \& Arnon (11) nos potes plásticos. Os postes plásticos foram envolvidos por papel alumínio para simular a falta de claridade do solo. A solução nutritiva foi trocada a cada três dias. Os potes foram dispostos em delineamento experimental inteiramente casualizado, com 14 tratamentos (espécies do gênero Passiflora) e cinco repetições, sendo uma mantida como testemunha (planta não inoculada). Avaliou-se o período de sobrevivência (período em dias da inoculação até a morte das plantas) e números de plantas vivas. Essas avaliações foram realizadas diariamente até os 40 dias após a inoculação. Durante as avaliações, segmentos do caule e das raízes das plantas sintomáticas foram selecionados para o reisolamento do fungo, a fim de completar o postulado de Koch.

Após as avaliações, os dados que apresentaram distribuição normal foram submetidos a análise de variância e as médias comparadas pelo Teste de Tukey a nível de $5 \%$ de probabilidade. Também foram feitas dispersão gráfica através das médias das características e gráfico. As análises estatísticas foram realizadas no programa genes (6).

\section{RESULTADOS E DISCUSSÃO}

$\mathrm{Na}$ avaliação de resistência/suscetibilidade das 14 espécies de Passiflora ao fungo F. oxysporum f. sp. passiflorae (FOP) observouse que do total de 56 plantas inoculadas, 41 haviam morrido após 40 dias de avaliações. O patógeno foi isolado das plantas mortas, sendo confirmando a causa da morte.

O período de sobrevivência das espécies variaram de 16,25 a 38,25 dias. A espécie que teve maior período de sobrevivência foi $P$. morifolia, sendo esta a mais resistente ao patógeno, porem diferiu apenas das espécies P. alata e P. micropetala. As espécies com menor período de sobrevivência foram $P$. micropetala e $P$. alata, sendo consideradas as mais suscetíveis a fusariose.

$\mathrm{Na}$ figura 1 observa-se os sintomas da doença nos genótipos inoculados comparando com as testemunhas. Foi possível notar nas plantas inoculadas o apodrecimento do sistema radicular devido a colonização do sistema vascular pelo fungo. Já as plantas testemunhas, apresentam sistema radicular desenvolvido e com emissão de novas raízes. Também constatou-se uma redução no crescimento das plantas inoculadas em comparação com as testemunhas. Antes de ocorrer a murcha, as folhas mudam a coloração de verde-brilhante para verdepálido ou verde amarelado. Pode-se observar mudança na coloração dos tecidos do xilema, com a ocorrência de coloração ferruginosa, sintomas característicos da doença. Em todas as plantas murcha foram

Tabela 1. Período médio de dias de sobrevivência de 14 espécies de Passisflora inoculadas com $\boldsymbol{F}$. oxysporum $\boldsymbol{f}$. $\mathrm{sp}$. Passiflorae. Cáceres, Mato Grosso, 2014

\begin{tabular}{cc}
\hline Espécie & Período de sobrevivência \\
\hline P. morifolia & $\mathrm{a} 38,25$ \\
P. nitida & $\mathrm{ab} 34,75$ \\
P. mucronata & $\mathrm{ab} 34,75$ \\
P. foetida & $\mathrm{ab} 33$ \\
P. tenuifila & $\mathrm{ab} 31$ \\
P. cincinnata & $\mathrm{ab} 30$ \\
P. edulis & $\mathrm{ab} 29,75$ \\
P. suberosa & $\mathrm{ab} 28,75$ \\
P. eichleriana & $\mathrm{ab} 24,5$ \\
P. setacea & $\mathrm{ab} 21$ \\
P. quadrangulares & $\mathrm{ab} 19,5$ \\
P. coccinea & $\mathrm{ab} 19,5$ \\
P. micropetala & $\mathrm{b} 17$ \\
P. alata & $\mathrm{b} 16,25$ \\
\%CV & $27,8 \%$
\end{tabular}

*Médias seguidas de mesma letra não diferem estatisticamente entre si. Pelo teste de Tukey a $5 \%$ de probabilidade. CV\%: coeficiente de variação. 

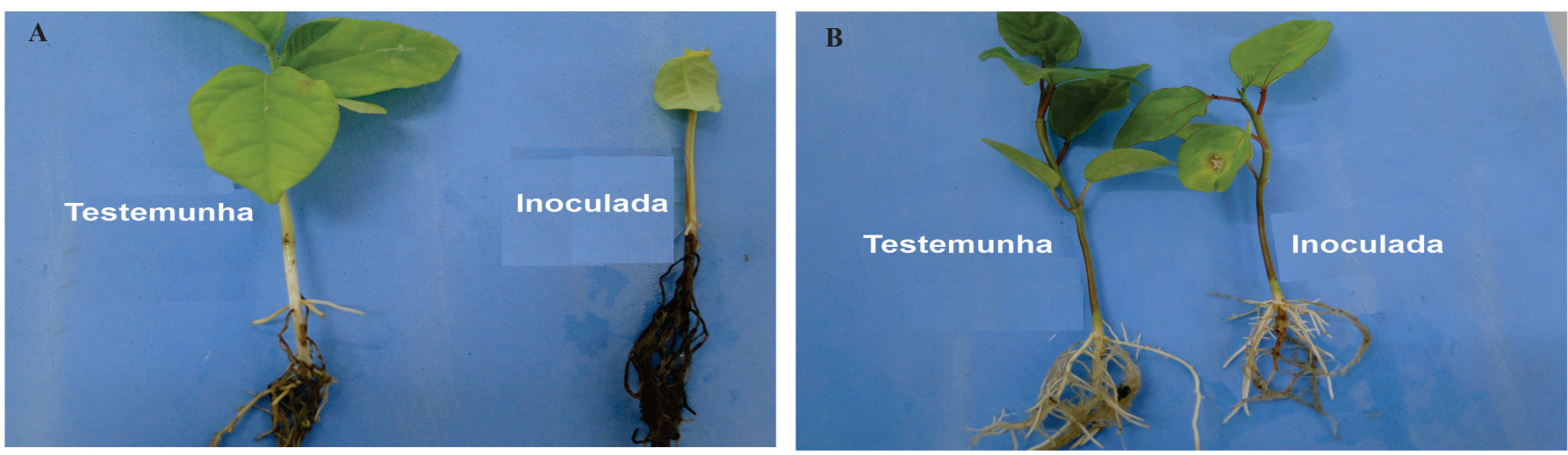

Figura 1. Genótipos de Passiflora alata (A) e de P. edulis (B) inoculados com uma suspensão de esporos de F. oxysporum f. sp. passiflorae e plântulas não inoculadas (testemunha). Cáceres, Mato Grosso, 2014.

observados esses sintomas.

Em muitas plantas avaliadas foram observados a formação de várias raízes adventícias. Essa reação das plantas, assim como alterações do crescimento e hiperplasia do parênquima foram relatados em outros trabalhos $(10,18,24)$. A eficiência na emissão de várias raízes secundarias pode estar associado a longevidade das espécies sobreviventes.

Os sintomas de murcha surgiram aos sete dias de avaliações. A primeira morte ocorreu aos nove dias com um genótipo da espécie $P$. suberosa. Houve uma concentração de morte entre os 16 e 19 dias. Resultados parecidos foram encontrado no trabalho de Silva et al. (23), os sintomas surgiram aos 7 dias após a inoculação, sendo a maioria das plantas apresentaram sintomas aos 34 dias.

Como a manifestação da fusariose ocorre em plantas adultas e é muito influenciada pelo solo, clima e interações com o patógeno (20), torna-se muito difícil a seleção de plantas resistentes na fase inicial. Mas o método utilizado neste estudo para avaliação de fusariose nas plantas no estágio de muda foi eficiente. O sucesso desta inoculação se deve ao tempo maior de exposição das raízes aos conídios, aumentando a possibilidade de penetração do patógeno. O período de avaliação foi bem reduzido além de propiciar uma boa distinção das plantas resistente. Vários trabalhos realizados com inoculação de $F$. oxysporum corroboram com a eficiência da metodologia de inoculação por imersão das raízes em suspensão contendo o patógeno por um determinado período $(19,22)$. No entanto, não encontra trabalhos utilizando solução nutritiva para o desenvolvimento das plantas. Substituir o solo por solução nutritiva possibilitou acompanhar a evolução da doenças nas raízes.

Conforme a dispersão gráfica (inserir Figura 2) obtida através das características de resistência/suscetibilidade foram formados quatro grupos. No primeiro grupo estão as espécies mais suscetíveis, com período máximo de sobrevivência de 25 dias (inserir Figura 3). As espécies que formaram esses grupos são: $P$. alata, $P$. micropetala, $P$. quadrangularis, $P$. coccinea, $P$. setacea, P. eichleriana. Compreendeu

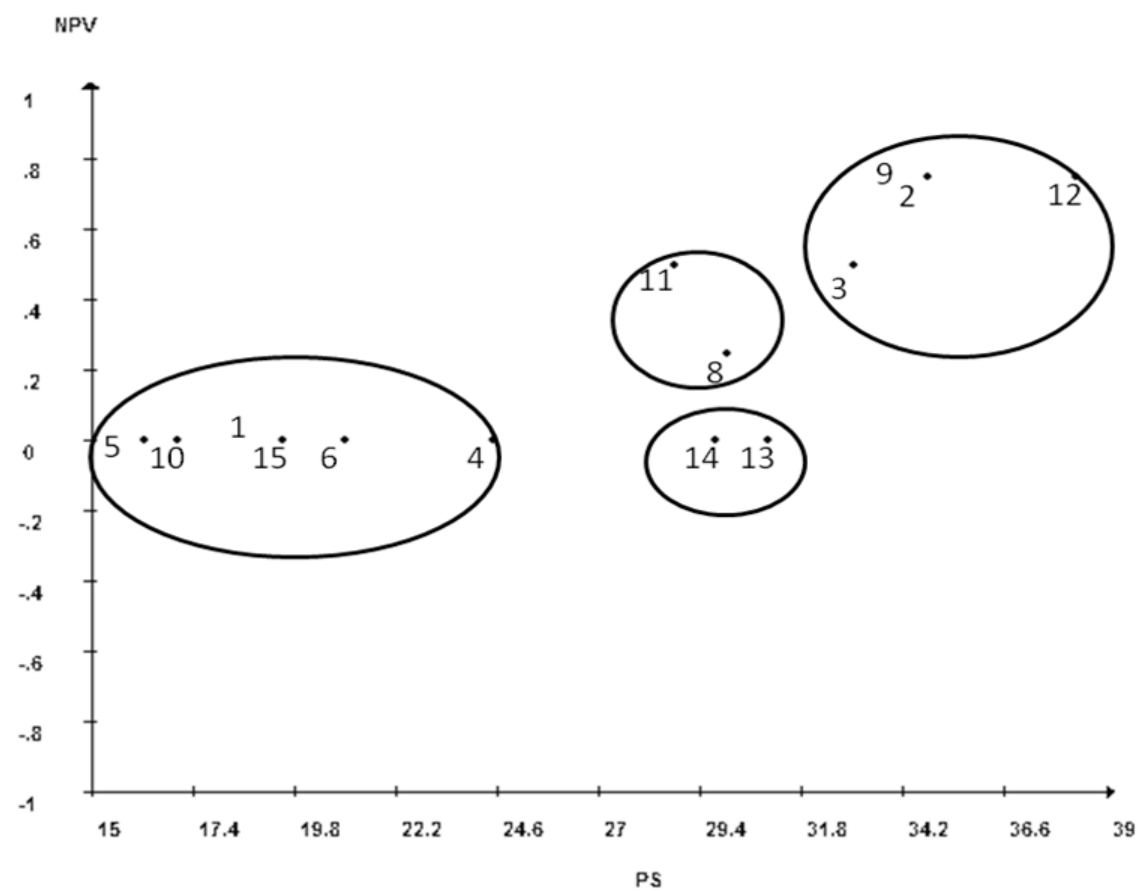

Figura 2. Dispersão gráfica das características: número de plantas vivas-NPV (média de 4 plantas) e período de sobrevivência-PS (média de 4 plantas) para as espécies $P$. quadrangularis $1, P$. nitida 2, P. foetida 3 , P. eichleriana 4, P. alata 5 , P. setacea $6, P$. cincinnata $8, P$. mucronata $9, P$. micropetala 10, P. suberosa 11, P. morifolia 12, P. tenuifila 13, P. edulis 14, P. coccinea 15. Cáceres, Mato Grosso, 2014 


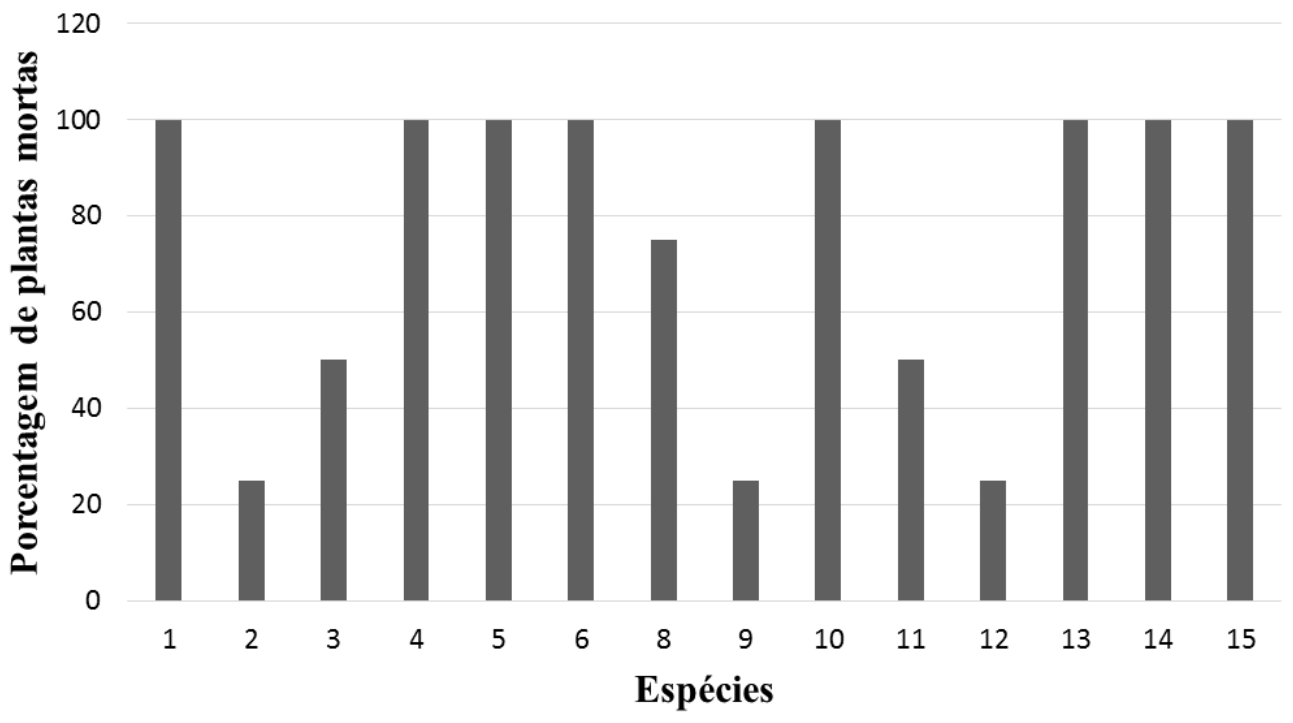

Figura 3. Distribuição da porcentagem de plantas mortas de cada espécie de Passiflora por $F$. oxysporum f. sp. Passiflorae. Sendo as espécies $P$. quadrangularis 1, P. nitida 2, P. foetida 3 , P. eichleriana 4, P. alata 5, P. setacea 6 , P. cincinnata 8, P. mucronata 9 , P. micropetala 10, , P. suberosa 11, P. morifolia 12, P. tenuifila 13, P. edulis 14, P. coccinea 15. Cáceres, Mato Grosso, 2014.

a maioria das plantas $(42,86 \%)$.

O segundo grupo foi formado pelas espécies $P$. edulis e $P$. tenuifila. Os genótipos de $P$. edulis sobreviveram até os 31 dias. Nenhum genótipo desse grupo sobreviveu aos 40 dias de avaliação (Figura 3).

O terceiro grupo alocou as espécies $P$. suberosa e $P$. cincinnata. Essas espécies foram consideradas moderadamente resistentes. Em média, sobreviveram 30 dias. No entanto, algumas plantas sobreviveram até o final das avaliações, sendo dois genótipos de $P$. suberosa e um de $P$ cincinnata.

Por último, as espécies mais resistentes foram $P$. foetida, $P$. mucronata, $P$. nitida e $P$. morifolia. Essas espécies sobreviveram por um período maior, além de metade dos genótipos avaliados sobrevirem os 40 dias de avaliações (Figura 3).

A espécie P. suberosa apresentou moderada resistência devido alguns plantas sobreviverem aos 40 dias de avaliações (Figura 3), embora o primeiro genótipo a morrer seja dessa espécie. Morwani (16) também constatou plantas resistente de Passiflora suberosa. Os genótipos de P. edulis e P. alata utilizado neste estudo foram suscetíveis. No entanto, alguns trabalhos realizado com estas espécies encontraram genótipos resistentes $(10,16,22)$. Esta divergências encontrada nos trabalhos é explicada pelo fato do maracujazeiro azedo e doce serem espécies alógamas e auto-incompatíveis $(3,14)$, assim possui uma grande variabilidade genética. Outra explicação seria a variabilidade entre os isolados do patógeno, já constatada em alguns estudos $(4,7,23)$.

Outra espécie que apresentou resistência moderada foi a $P$. cincinnata. O trabalho realizado por Silva et al. (22), corroboram com este resultado. As espécies mais resistentes foram $P$. foetida, $P$. mucronata, $P$. nitida e $P$. morifolia. A espécie $P$. nitida apresenta grande potencial para utilização em programas de melhoramento em virtude de ser resistente a vários patógenos de solo $(12,21)$. Estes genótipos resistentes podem ser utilizados como porta enxerto ou em hibridação interespecífica em programa de melhoramento.

Variabilidade genética intraespecífica foi observado na maioria das espécies em relação a resistência ao FOP, embora o número de plantas avaliado seja pequeno. Essa variabilidade deve ser mais exploradas, realizando seleção com maior número de genótipos e de espécies diferentes. Também é importantes utilizar vários isolados do patógeno. Assim é possível obter um uma acurácia maior no screening.

$\mathrm{O}$ desenvolvimento de metodologias para diagnose precoce e rápida de FOP em maracujazeiro auxiliará programas de melhoramento no screening de germoplasma. Já que, selecionar genótipos no campo resistentes ao FOP não é viável devido os sintomas da doença aparecerem lentamente em plantas adultas e o progresso da doença é afetado pela densidade de inoculo, distribuição no campo e as condições ambientais (10). No entanto, neste estudo foi possível selecionar plantas resistentes em pouco tempo e espaço.

Apesar de várias contribuições importantes sobre a fusariose do maracujazeiro causada pelo FOP, ainda carece ser mais pesquisado, por ser uma doença limitante para a cultura do maracujazeiro. Mais trabalhos devem ser desenvolvidos para contribuir com o controle eficiente desta doença.

A metodologia utilizada possibilitou a seleção de genótipos em estádio de muda. Também permitiu observar a evolução da doença nas raízes. Houve variabilidade genética dentro das espécies em relação a resistência ao FOP. As espécies mais resistentes foram $P$. foetida, $P$. mucronata, P. nitida e P. morifolia.

\section{REFERÊNCIAS}

1. Agrios, G.N. Plant Pathology. $5^{\text {rd }}$ ed. Amsterdam The Netherlands: Elsevier Academic Press, 2005, 922p.

2. Barbosa, R.J.F.; Meza, C.L.S. Antagonismo in Vitro de Trichoderma harzianum Rifai sobre Fusarium oxysporum Schlecht f. sp passiflorae en Maracuyá (Passiflora edulis Sims var. Flavicarpa) de Municipio Zona Bananera Colombiana. Revista Facultad Nacional Agropecuaria Medellín, Bogotá, v. 62, n. 1, p. 4743, 2009.

3. Bruckner, C.H.; Casali, V.W.D.; Moraes, C.F.; Regazzi, A.J.; Silva, E.A.M. Self-incompatibility in passion fruit (Passiflora edulis Sims). Acta Horticulturae, Wageningen, v.370, p.45-57, 1995.

4. Carvalho, A.B.; Coelho, V.J.E.; Araujo, K.L.; Siqueira, K.A.A.; Neves, S.M.A.S.; Soares, M.A.; Neves, L.G. Genetic variability of Fusarium solani and Fusarium oxysporum f. sp. passiflorae isolates from Pantanal, 
Amazon and Cerrado biomes of Mato Grosso, Brazil. African Journal of Agricultural Research, Lagos, v. 10, n. 53, p. 4990-4997, 2015.

5. Cavichioli, J.C.; Corrêa, L.S.; Boliani, A.C.; Santos, P.C. Desenvolvimento e produtividade do maracujazeiro-amarelo enxertado em três porta-enxertos. Revista Brasileira de Fruticultura, Jaboticabal, v. 33, n. 2, p. 567-574, 2011

6. Cruz, C.D. GENES: a software package for analysis in experimental statistics and quantitative genetics. Acta Scientiarum Agronomy, Maringá, v. 35, n. 3, p. 271-276, 2013

7. Dariva, J.; Xavier, A.A.; Costa, M.R.; Ribeiro, R.C.F.; Sousa, T.V. Genetic variability of Fusarium solani and Fusarium oxysporum f. sp. Passiflorae isolated associated with passion fruit. Revista Brasileira de Fruticultura, Jaboticabal, v. 37, n. 2, p. 377-386, 2015.

8. Ferreira, R.; Rodrigue, A.; Catarino, A. Utilização do resíduo orgânico da casca de mandioca no controle de Fusarium oxysporum $f$. sp. passiflorae em maracujazeiro amarelo, Cadernos de Agroecologia, Fortaleza, v. 6, n. 2, p. 2236-7934, 2012

9. Flores, P.S.; Bruckner, C.H. Raios gama na sobrevivência de plantas de maracujazeiro amarelo inoculadas com Fusarium oxysporum $f$. sp. passiflorae. Ciência Rural, Santa Maria, v.44, n.4, p.639-644, 2014.

10. Flores, P.S.; Otoni, W.C.; Dhingra, O.D.; Diniz, S.P.S.S.; Santos, T.M.; Bruckner, C.H. In vitro selection of yellow passion fruit genotypes for resistance to Fusarium vascular wilt. Plant Cell Tiss Organ Cult, Cham, v. 108, n. 1, p. 37-45, 2012.

11. Hoagland, D.R..; Arnon, D.I. The water culture method for growing plants without soils. Berkeley, California Agricultural Experimental Station, 1950, 32p.

12. Junqueira, N.T.V.; Lage, D.A.C.; Braga, M.F.; Peixoto, J.R.; Borges, T.A.; Andrade, S.E.M. Reação a doenças e produtividade de um clone de maracujazeiro-azedo propagado por estaquia e enxertia em estacas de Passiflora silvestre. Revista Brasileira de Fruticultura, Jaboticabal, v. 28, n. 1, p. 97-100, 2006.

13. Laranjeira, F.F.; Lima, A.A.; Costa, M.M.; Pfenning, L. Progresso da fusariose do maracujá em porta-enxertos do gênero Passiflora. Fitopatologia Brasileira, Brasília, v. 30, p.146, 2005.

14. Malerbo-Souza, D.T.; Ribeiro, M.F. Polinização do maracujá doce (Passiflora alata Dryander). Scientia Agraria Paranaensis, Marechal Cândido Rondon, v.9, n.2, p.37-46, 2010.
15. McKnight, T. A wilt disease of the passion vines (Passiflora edulis) caused by a species of Fusarium. Queensland Journal of Agricultural Science, Brisbane, v.8, n.1, p. 1-4, 1951.

16. Morwani, G.R. Screening Passiflora Species For Drought Tolerance, Compatibility With Purple Passion Fruit, Fusarium Wilt Resistance And The Relationship Between Irrigation, Drenching And Media Composition In The Control Of Fusarium Wilt. 2008. 230f. Tese (Doutorado em Philosophy) - Ohio State University, Ohio.

17. Navas-Cortés, J.A.; Landa, B.B.; Rodríguez-López, J.; Jiménez-Díaz, R.M.; Castillo, P. Infection by Meloidogyne artiellia does not break down resistance to races 0,1A, and 2 of Fusarium oxysporum f. sp. ciceris in chickpea genotypes. Phytopathology, Saint Paul, v.98, n.6, p. 709-718, 2008.

18. Ortiz, E.; Cruz, M.; Melgarejo, L.M.; Marquínez, X.; Hoyos-Carvajal, L. (2014) Histopathological features of infections caused by Fusarium oxysporum and F. solani in purple passionfruit plants (Passiflora edulis Sims). Summa Phytopathologica, Botucatu, v. 40, n. 2, p. 134-140, 2014

19. Pereira, M.J.Z.; Ramalho, M.A.P.; Abreu, A.D.F.B. Reação de linhagens de feijoeiro ao fungo Fusarium oxysporum $f$. sp. phaseoli em condições controladas. Ciência e Agrotecnologia, Lavras, v. 35, n. 5, p. 940 -947, 2011.

20. Predieri, S. Mutation induction and tissue culture in improving fruits. Plant Cell Tiss Org Cult, Cham, v. 64, n. 2-3, p. 185-210, 2001.

21. Preisigke, S.C.; Neves, L.G.; Araujo, K.L.; Barbosa, N.R.; Serafim, M.E.; Krause, W. Multivariate analysis for the detection of Passiflora species resistant to collar rot. Bioscience Journal, Uberlandia, v. 31, n. 6, p. 1700-1707, 2015.

22. Silva, A.S.; Oliveira, E.J.; Haddad, F.; Laranjeira, F.F.; Jesus, O.N.; Oliveira, S.A.S.; Costa, M.A.P.C.; Freitas, J.P.X. Identification of passion fruitn genotypes resistant to Fusarium oxysporum f. sp. passiflorae. Tropical Plant Pathology, Brasilia, v. 38, n. 3, p. 236-242, 2013.

23. Silva, A.S.; Oliveira, E.J.; Haddad, F.; Jesus, O.N.; Oliveira, S.A.S.; Costa, M.A.P.C. Molecular fingerprinting of Fusarium oxysporum $\mathrm{f}$. sp. passiflorae isolates using AFLP markers. Scientia Agricola, Piracicaba, v. 70, n. 2, p. 108-115, 2013.

24. Siqueira, L. Growth regulators in the plant disease. Annual Review of Phytopathology, Palo Alto, v. 1, n. 1, p. 5-30, 1963

25. Viana, F.M.P.; Costa, A.F. Doenças do maracujazeiro. In: Freire, F.C.O; Cardoso, J.E.; Viana, F.M.P. (eds) Doenças de fruteiras tropicais de interesse agroindustrial. Brasília: EMBRAPA, 2013, p.269-322 (In Portuguese). 